\title{
SUSTENTABILIDADE, GLOBALIZAÇÃO, TECNOLOGIA E CONSUMO: ESTRATÉGIAS DE GOVERNANÇA GLOBAL
}

\author{
SUSTAINABILITY AND GLOBALIZATION, AND CONSUMER TECHNOLOGY: \\ STRATEGIES FOR GLOBAL GOVERNANCE
}

\section{Sonia Aparecida de Carvalho ${ }^{1}$}

SUMÁRIO: Considerações iniciais; 1 . A tecnologia como um instrumento de sustentabilidade; 2 . A globalização e o consumo como governança transnacional; 3. A desgovernança ambiental global; Considerações finais; Referências das fontes citadas.

RESUMO: O artigo debate a sustentabilidade, a globalização, a tecnologia e o consumo como estratégias de governança global. O objetivo geral consiste em pesquisar a relação inerente entre a sustentabilidade e as implicações da tecnologia, da globalização e do consumo, no âmbito local e global. Como objetivos específicos pretende considerar a tecnologia como um instrumento de sustentabilidade, de maneira que o desenvolvimento da sustentabilidade e da tecnologia busque o equilíbrio entre os fatores econômicos, sociais, ambientais e tecnológicos; pesquisar as consequências da globalização e do consumo como uma governança transnacional e mundial; analisar a desgovernança ambiental global, referente ao modo de governança política da sociedade, Instituições e Estados, atinente ao modelo de desenvolvimento social, econômico, ambiental e humano. O método de procedimento utilizado no artigo consiste na apreciação e interpretação da matéria e o método de pesquisa usado incide na elaboração, por meio de análise bibliográfica, utilizando-se das referências citadas.

Palavras-chave: Consumo; Governança; Globalização; Sustentabilidade; Tecnologia.

ABSTRACT: The article discusses sustainability, globalization, technology and

\footnotetext{
1 Docente do Curso de Direito Universidade Norte do Paraná - UNOPAR - PR. Mestra em Direito pela Universidade de Santa Cruz do Sul - UNISC - RS. Especialista em Direito do Trabalho pela Universidade Castelo Branco - UCB - RJ. Especialista em Direito Ambiental pela Universidade Norte do Paraná - UNOPAR - PR. Especialista em Direito Previdenciário por esta mesma Instituição. email: sonia.adv.2008@hotmail.com.
} 
CARVALHO, Sonia Aparecida de. Sustentabilidade, Globalização, Tecnologia e Consumo: estratégias de Governança Global. Revista Eletrônica Direito e Política, Programa de Pós-Graduação Stricto Sensu em Ciência Jurídica da UNIVALI, Itajaí, v.10, n.1, edição especial de 2015. Disponível em: www.univali.br/direitoepolitica - ISSN 1980-7791.

consumption strategies for global governance. The overall objective is to find the inherent relationship between sustainability and the implications of technology, globalization and consumption, locally and globally. Specific objectives aimed to consider technology as a tool for sustainability, so that the development of sustainability and technology seeks balance between economic, social, environmental and technological factors; investigate the consequences of globalization and consumption as a transnational and global governance; analyze global environmental disgovernance, that refers to the political governance of society, institutions and regard to, economic, environmental, human and social development model states. The method of procedure used in this paper consists in the examination and interpretation of matter and the research method used focuses on the design, through literature analysis, using the references cited.

KEYWORDS: Consumption; Governance; Globalization; Sustainability; Tech.

\section{CONSIDERAÇÕES INICIAIS}

O artigo versa a sustentabilidade, a globalização, a tecnologia e o consumo como estratégias de governança ambiental transnacional e global, assim como trata as questões econômicas, sociais, políticas, culturais e ambientais, de modo interligado, em escala local e global.

Nessa perspectiva, o artigo propõe questionar que, com o advento da modernidade, ocorrem transformações econômicas, sociais, políticas, culturais e ambientais, em escala transnacional e mundial, como as implicações da crise socioeconômica e da crise ambiental, e as consequências do avanço da globalização, da tecnologia e do consumo na governança da sustentabilidade global.

Inicialmente, na primeira etapa, considera-se o desenvolvimento e o progresso da tecnologia como um instrumento de sustentabilidade, em sua relação intrínseca com a tecnologia, pois proteger o meio ambiente e/ou a natureza e o ser humano são os objetivos da técnica.

Posteriormente, na segunda etapa, avalia-se o avanço e as consequências da globalização e do consumo e as interações econômicas, sociais, políticas e culturais como governança transnacional e mundial. Finalmente, na terceira etapa, analisa-se a desgovernança da sustentabilidade ambiental e política, em 
CARVALHO, Sonia Aparecida de. Sustentabilidade, Globalização, Tecnologia e Consumo: estratégias de Governança Global. Revista Eletrônica Direito e Política, Programa de Pós-Graduação Stricto Sensu em Ciência Jurídica da UNIVALI, Itajaí, v.10, n.1, edição especial de 2015. Disponível em: www.univali.br/direitoepolitica - ISSN 1980-7791.

escala planetária, e a governança global da sustentabilidade, na busca de uma sociedade moderna, justa, inclusiva e sustentável.

\section{A TECNOLOGIA COMO UM INSTRUMENTO DE SUSTENTABILIDADE}

As transformações mundiais das últimas décadas, aquelas vinculadas à degradação ambiental e à crescente desigualdade social entre os países, promovem estratégias de governança transnacional global. Articulam-se, de um lado, os impactos da crise socioeconômica e a necessidade de repensar os atuais modelos de desenvolvimento dos países; e, de outro lado, a crise ecológica e/ou ambiental e a necessidade de reflexão dos riscos ambientais globais e locais. Com o advento da modernidade, grandes transformações ocorrem na sociedade. $\mathrm{Na}$ modernidade, houve o avanço da tecnologia e do consumo que, se por um lado, facilitou e aumentou a produção, por outro lado, substituiu a produção e o laboro do ser humano pela máquina e pela tecnologia.

A humanidade avança em direção ao desenvolvimento tecnológico e ao controle da natureza; porém, se esse avanço trouxe benefícios, também apresenta malefícios para o meio ambiente e para o ser humano, pois coloca em risco a sua própria sobrevivência, como resultado dos crescentes desequilíbrios provocados pela contínua interferência do homem sobre a natureza e/ou recursos naturais. ${ }^{2}$

Por isso, quando analisa o ser humano e o planeta ameaçados, Jonas ${ }^{3}$ salienta que "só uma ética que nos responsabilize a todos pode cumprir o papel de apontar os valores e os fins a serem perseguidos e a utilizar os meios como aquilo que realmente são, sem transformá-los em fins em si mesmos". O compromisso da tecnologia moderna converteu-se em ameaça, e a ciência protesta por uma ética que impeça o poder dos seres humanos de se transformarem em uma desgraça para eles mesmos.

\footnotetext{
2 LUIZ, Leliana Aparecida Casagrande. Educação ambiental e desenvolvimento sustentável: gestão ambiental. São Paulo: Pearson Prentice Hall, 2009, p. 3-5.

3 JONAS, Hans. O princípio responsabilidade: ensaio de uma ética para a civilização tecnológica. Tradução de Marijane Lisboa; Luiz Barros Montez. Rio de Janeiro: Contraponto; PUC-RJ, 2006, p. 19.
} 
CARVALHO, Sonia Aparecida de. Sustentabilidade, Globalização, Tecnologia e Consumo: estratégias de Governança Global. Revista Eletrônica Direito e Política, Programa de Pós-Graduação Stricto Sensu em Ciência Jurídica da UNIVALI, Itajaí, v.10, n.1, edição especial de 2015. Disponível em: www.univali.br/direitoepolitica - ISSN 1980-7791.

Ao estabelecer o princípio da responsabilidade, Jonas ${ }^{4}$ afirma que "está pensando menos no perigo da pura e simples destruição física da humanidade, mas sim na sua morte essencial, aquela que advém da desconstrução e da aleatória reconstrução tecnológica do homem e do ambiente". O princípio da responsabilidade tem que ter um significado ético, não pode referir-se unicamente à natureza como abstração, mas antes se relaciona com o meio ambiente natural da vida humana. Este pensamento expressa que não se deve pôr em perigo a continuidade da humanidade na Terra.

Também em relação ao comportamento humano, o mesmo autor comenta que "a ética da responsabilidade é princípio primordial e norteador dos paradigmas, no qual o ser humano busca categorias que o ajudem a continuar vivendo uma vida digna e merecendo o nome de humana". ${ }^{5}$ O princípio da responsabilidade significa o dever de obrigação de cada geração de respeitar o meio ambiente como condição para a existência das próximas gerações. Para Jonas", "a solidariedade de destino entre o ser humano e a natureza faz igualmente redescobrir a dignidade autônoma da natureza e obriga a respeitar a sua integralidade, além do aspecto utilitário". Existe uma dupla responsabilidade de solidariedade entre os seres vivos e os seres humanos.

No entanto, ao estabelecer os modelos de vida, os valores e os imperativos que norteiam a conduta humana, não foi considerada a relação de integração e dependência do ser humano com a natureza.

A promessa da tecnologia moderna se converteu em ameaça, ou esta se associou àquela de forma indissolúvel. [...] Concebida para a felicidade humana, a submissão da natureza, na sobremedida de seu sucesso, que agora se

\footnotetext{
${ }^{4}$ JONAS, Hans. O princípio responsabilidade: ensaio de uma ética para a civilização tecnológica. p. 18.

5 JONAS, Hans. 0 princípio responsabilidade: ensaio de uma ética para a civilização tecnológica. p. 19.

6 JONAS, Hans. O princípio responsabilidade: ensaio de uma ética para a civilização tecnológica. [s. p.].
} 
CARVALHO, Sonia Aparecida de. Sustentabilidade, Globalização, Tecnologia e Consumo: estratégias de Governança Global. Revista Eletrônica Direito e Política, Programa de Pós-Graduação Stricto Sensu em Ciência Jurídica da UNIVALI, Itajaí, v.10, n.1, edição especial de 2015. Disponível em: www.univali.br/direitoepolitica - ISSN 1980-7791.

estende à própria natureza do homem, conduziu ao maior desafio já posto ao ser humano pela sua própria ação. ${ }^{7}$

A sociedade e/ou o Estado contemporâneo devem desenvolver novas tecnologias que permitam o uso eficiente dos recursos naturais, sem causar danos ao meio ambiente e ao ser humano. Nessa perspectiva, há uma relação intrínseca entre a sustentabilidade, a globalização, a tecnologia e o consumo. Por conseguinte, proteger o meio ambiente e o ser humano são os objetivos da técnica, baseados na sustentabilidade. Entretanto,

A degradação ambiental, o risco do colapso ecológico, a globalização e o avanço da desigualdade e da pobreza são sinais eloquentes da crise do mundo globalizado. A sustentabilidade é o significante de uma falha fundamental na história da humanidade; crise de civilização que alcança seu momento culminante na modernidade, mas cujas origens remetem a concepção do mundo que serve de base à civilização ocidental. A sustentabilidade é o tema do nosso tempo, do final do século XX e da passagem para o terceiro milênio, da transição da modernidade truncada e inacabada para uma pós- modernidade incerta, marcada pela diferença, pela diversidade, pela democracia e pela autonomia. $^{8}$

O desenvolvimento da sustentabilidade e da tecnologia tem a finalidade de buscar o equilíbrio entre os fatores econômicos, sociais, ambientais e tecnológicos. Diante disso, existe uma relação intrínseca entre a sustentabilidade e a tecnologia. Portanto, implica uma inter-relação necessária de justiça social, qualidade de vida, equilíbrio ambiental e uso adequado da tecnologia.

No entanto, há um confronto de interesses das condições de sustentabilidade aos mecanismos do mercado. Por meio do processo de reapropriação econômica e social da natureza e da cultura, emerge uma racionalidade ambiental que propõe uma revalorização da vida do ser humano e da natureza.

O conceito de ambiente se defronta com as estratégias fatais da globalização. O princípio da sustentabilidade surge como

\footnotetext{
7 JONAS, Hans. O princípio responsabilidade: ensaio de uma ética para a civilização tecnológica. p. 67.

8 LEFF, Enrique. Saber ambiental: sustentabilidade, racionalidade, complexidade, poder. Tradução de Lúcia Mathilde Endlich Orth. 8. ed. Petrópolis: Vozes, 2011, p. 9.
} 
CARVALHO, Sonia Aparecida de. Sustentabilidade, Globalização, Tecnologia e Consumo: estratégias de Governança Global. Revista Eletrônica Direito e Política, Programa de Pós-Graduação Stricto Sensu em Ciência Jurídica da UNIVALI, Itajaí, v.10, n.1, edição especial de 2015. Disponível em: www.univali.br/direitoepolitica - ISSN 1980-7791.

uma resposta à fratura da razão modernizadora e como uma condição para construir uma nova racionalidade produtiva, fundada no potencial ecológico e em novos sentidos de civilização a partir da diversidade cultural do gênero humano. Trata-se da reapropriação da natureza e da reinvenção do mundo; não só de um mundo no qual caibam muitos mundos, mas de um mundo conformado por uma diversidade de mundos, abrindo o cerco da ordem econômico-ecológica globalizada. ${ }^{9}$

A sociedade moderna vive uma grave crise ecológica e social e a coletividade convive um impacto ecológico mundial das atividades de produção e consumo, demonstrando a insustentabilidade atual do modo de produção e consumo, no âmbito global. Segundo afirmam os autores, "el impacto ecológico mundial de las actividades de producción y consumo [...] ha crecido sin cesar hasta manifestarse en síntomas de una grave crisis ecológico-social", ${ }^{10}$ pois os atuais modelos de desenvolvimento, produção e consumo são estimulados e dominados pelo capitalismo.

A noção de sustentabilidade refere-se a três dimensões distintas, ou seja, a ecológica, a social e a econômica. A sustentabilidade propõe intensas transformações nas três dimensões para reorganizar a sociedade, em longo prazo. Trata-se de buscar novas formas de socialização, de organização social e econômica, que permitam romper com os atuais modelos de desenvolvimento, produção e consumo, que são impulsionados e dominados pelo capitalismo.

En el plano ecológico parece evidente considerar la inviabilidad de la vida humana y de las sociedades durante mucho tiempo si estas se desarrollan en contradicción con los límites y procesos que las sostienen. Somos seres ecodependientes y como tales vivimos y somos en la naturaleza. En la dimensión social, la sostenibilidad se relaciona con la capacidad de satisfacer las necesidades humanas de forma justa y con la condición de interdependencia que caracteriza a los seres humanos [...]. Desde el punto de vista económico, existen bienes, procesos $y$ trabajos que son los que permiten satisfacer las

\footnotetext{
${ }^{9}$ LEFF, Enrique. Saber ambiental: sustentabilidade, racionalidade, complexidade, poder. p. 31.

10 RIECHMANN, Jorge; REYES, Luis González; HERRERO, Yayo; MADORRÁN, Carmen. Qué hacemos hoy cuando nos encontramos frente a la amenaza de una crisis mayor que la económica: la ecológica. Madrid: Ediciones Akal, S. A., 2012, p. 8.
} 
CARVALHO, Sonia Aparecida de. Sustentabilidade, Globalização, Tecnologia e Consumo: estratégias de Governança Global. Revista Eletrônica Direito e Política, Programa de Pós-Graduação Stricto Sensu em Ciência Jurídica da UNIVALI, Itajaí, v.10, n.1, edição especial de 2015. Disponível em: www.univali.br/direitoepolitica - ISSN 1980-7791.

necesidades de las personas. Sin embargo estas tres patas no son iguales, sino que se asemejan a esas muñecas rusas que encajan unas dentro de otras. ${ }^{11}$

Consequentemente, buscar a sustentabilidade implica na transformação da dimensão social, econômica e ambiental. Nesse contexto, "la sostenibilidad es una noción positiva y altamente proactiva que supone la introducción de los câmbios necesarios para que la sociedad planetaria, constituida por la humanidad, sea capaz de perpetuarse indefinidamente en el tiempo"12, dito de outro modo, uma sociedade capaz de permanecer indefinidamente no tempo; consequentemente, a sustentabilidade busca uma sociedade global, constituída pela humanidade.

El paradigma actual de la Humanidad es la sostenibilidad. La voluntad de articular una nueva sociedad capaz de perpetuarse en el tiempo en unas condiciones dignas. El deterioro material del Planeta es insostenible, pero también es insostenible la miseria y la exclusión social, la injusticia y la opresión, la esclavitud y la dominación cultural y económica. ${ }^{13}$

É a manutenção das condições da natureza ou do ecossistema que tornam a vida humana possível, pois a sociedade não pode entrar em colapso com os sistemas naturais. Nessa linha, Cruz e Bodnar ${ }^{14}$ defendem que "a sustentabilidade importa em transformação social, sendo conceito integrador e unificante, isso implica na celebração da unidade ser humano e natureza, na origem e no destino comum". Disso se apreende que a sustentabilidade deve contribuir com os demais

11 RIECHMANN, Jorge; REYES, Luis González; HERRERO, Yayo; MADORRÁN, Carmen. Qué hacemos hoy cuando nos encontramos frente a la amenaza de una crisis mayor que la económica: la ecológica. Madrid: Ediciones Akal, S. A., 2012, p. 35-36.

12 REAL FERRER, Gabriel. Sostenibilidad, transnacionalidad y trasformaciones del Derecho. In: SOUZA, Maria Cláudia da Silva Antunes de; GARCIA, Denise Schmitt Siqueira et al (Orgs.). Direito ambiental, transnacionalidade e sustentabilidade. Itajaí: UNIVALI, 2013, p. 7-30. Disponível em: http://www.univali.br/ppcj/ebook. Acesso em: 10 set. 2013, p. 13.

13 REAL FERRER, Gabriel. Calidad de vida, medio ambiente, sostenibilidad y ciudadanía ¿construimos juntos el futuro? Novos Estudos Jurídicos - NEJ. Itajaí-SC, v. 17, n. 3, p. 310326, $\quad$ set./dez., $2012 . \quad$ Disponível $\quad$ http://siaiweb06.univali.br/seer/index.php/nej/article/view/4202/2413. Acesso em: 15 març. 2014, p. 319.

14 CRUZ, Paulo Márcio; BODNAR, Zenildo (Orgs.). Globalização, transnacionalidade e sustentabilidade. Itajaí: UNIVALI, 2012. Disponível em: http://www.univali.br/ppcj/ebook. Acesso em: 5 mai. 2013, p. 51. 
CARVALHO, Sonia Aparecida de. Sustentabilidade, Globalização, Tecnologia e Consumo: estratégias de Governança Global. Revista Eletrônica Direito e Política, Programa de Pós-Graduação Stricto Sensu em Ciência Jurídica da UNIVALI, Itajaí, v.10, n.1, edição especial de 2015. Disponível em: www.univali.br/direitoepolitica - ISSN 1980-7791.

princípios constitucionais e com a atuação conjunta da sociedade civil do Estado, deve buscar a governança com sustentabilidade ecológica e social. ${ }^{15}$

A sustentabilidade implica em que o desenvolvimento da sociedade sustentável não pode desconhecer as dimensões culturais, as relações de poder existentes e o reconhecimento das limitações ecológicas, com o intuito de manter o modelo de desenvolvimento insustentável. ${ }^{16}$ Do mesmo modo, Jacobi ${ }^{17}$ menciona que "a sustentabilidade, como novo critério básico e integrador, precisa estimular permanentemente as responsabilidades éticas, na medida em que a ênfase nos aspectos extraeconômicos serve para reconsiderar os aspectos relacionados com a equidade, a justiça social e a ética dos seres vivos", pois reforça o comprometimento de responsabilização da sociedade e de constituição de valores éticos.

Assim, quando se fala em sustentabilidade, pensa-se na sustentabilidade ambiental, porque se necessita do entorno para sobreviver. Mas, quando se pensa em uma sociedade, não se trata somente de pensar em sobreviver, mas em criar uma sociedade global mais justa. Para isso, é preciso falar nas dimensões ambiental, social, econômica e tecnológica. É necessário buscar uma sociedade que possa resolver os problemas da injustiça social, bem como os demais Objetivos de Desenvolvimento do Milênio.

A partir de los Objetivos del Milenio y de la Conferencia de Johannesburgo se ha ido consolidan lo concepto de sostenibilidad y la triple dimensión en la que se proyecta, la ambiental, la social y la económica. [...] En definitiva, de lo que se trata es de encontrar una nueva forma de relación, más armónica, con nuestro entorno natural, por una parte, y con nuestros semejantes, por otra. ${ }^{18}$

15 CRUZ, Paulo Márcio; BODNAR, Zenildo (Orgs.). Globalização, transnacionalidade e sustentabilidade. p. 52.

16 JACOBI, Pedro Roberto. Meio ambiente e sustentabilidade. In: CEPAM. O Município no século XXI: cenários e perspectivas. São Paulo: CEPAM, 1999, p. 175-183. Disponível em: http://pt.scribd.com/doc/7506458/Meio-Ambiente-e-Sustentabilidade. Acesso em: 15 abr. 2014, p. 179.

17 JACOBI, Pedro Roberto. Meio ambiente e sustentabilidade. In: CEPAM. O Município no século XXI: cenários e perspectivas. p. 180.

18 REAL FERRER, Gabriel. Calidad de vida, medio ambiente, sostenibilidad y ciudadanía ¿construimos juntos el futuro? Novos Estudos Jurídicos - NEJ. p. 319-320. 
CARVALHO, Sonia Aparecida de. Sustentabilidade, Globalização, Tecnologia e Consumo: estratégias de Governança Global. Revista Eletrônica Direito e Política, Programa de Pós-Graduação Stricto Sensu em Ciência Jurídica da UNIVALI, Itajaí, v.10, n.1, edição especial de 2015. Disponível em: www.univali.br/direitoepolitica - ISSN 1980-7791.

O conceito de sustentabilidade fundamenta-se na tripla dimensão: a econômica, a social e a ambiental, que regula de forma justa e harmônica o ambiente natural com os semelhantes e estabelece relações e interações mútuas entre os seres humanos e a natureza.

Portanto, a sustentabilidade econômica propõe aumentar a geração de riqueza de forma ambientalmente sustentável, bem como encontrar mecanismos para uma distribuição justa e uniforme; já a sustentabilidade social propõe construir uma sociedade harmônica e integrada, para garantir o acesso aos bens e serviços de forma igualitária e sustentável e a sustentabilidade ambiental propõe buscar o equilíbrio da natureza, a fim de garantir a sobrevivência e o futuro das presentes e futuras gerações.

\section{A GLOBALIZAÇÃO E O CONSUMO COMO GOVERNANÇA TRANSNACIONAL}

Nas últimas décadas, as interações econômicas, sociais, políticas e culturais intensificaram devido ao fenômeno da globalização. A globalização trata "de um processo complexo que atravessa as diversas áreas da vida social, da globalização dos sistemas produtivos e financeiros à revolução nas tecnologias e [...] das novas práticas culturais e identitárias aos estilos de consumo globalizado". ${ }^{19}$ Os processos da globalização consistem em um fenômeno múltiplo com dimensões econômicas, sociais, políticas e culturais, interligadas de modo complexo, em escala local e global. Santos $^{20}$ entende que "a produção de globalização é o conjunto de trocas desiguais pelo qual um determinado artefacto, condição, entidade ou identidade local estende a sua influência para além das fronteiras nacionais", ou seja, o local e o global são socialmente produzidos dos modos de processos de globalização.

19 SANTOS, Boaventura de Sousa. Os processos da globalização. In: SANTOS, Boaventura de Sousa (Org.). A globalização e as ciências sociais. 2. ed. São Paulo: Cortez, 2002, p. 11.

20 SANTOS, Boaventura de Sousa. Os processos da globalização. In: SANTOS, Boaventura de Sousa (Org.). A globalização e as ciências sociais. p. 63. 
CARVALHO, Sonia Aparecida de. Sustentabilidade, Globalização, Tecnologia e Consumo: estratégias de Governança Global. Revista Eletrônica Direito e Política, Programa de Pós-Graduação Stricto Sensu em Ciência Jurídica da UNIVALI, Itajaí, v.10, n.1, edição especial de 2015. Disponível em: www.univali.br/direitoepolitica - ISSN 1980-7791.

A modernidade baseia-se em um processo no qual a noção de lugar e de espaço, que prevalece nos tempos modernos, é gradualmente extinguida por um conceito de tempo universal. As sociedades pré-modernas, por sua vez, fundamentam-se em relações sociais que são adequadas no tempo e no espaço. Compreende-se que a expressão no tempo e no espaço significa que os processos globalizadores não têm a mesma unidade de causas e consequências sociais, pois conforme Bauman"21, "os usos do tempo e do espaço são acentuadamente diferenciados e diferenciadores. A globalização tanto divide como une; divide enquanto une - e as causas da divisão são idênticas às que promovem a uniformidade do globo". Nesse sentido, afirma Giddens ${ }^{22}$, que "a globalização se refere essencialmente a este processo de alongamento, na medida em que as modalidades de conexão entre diferentes regiões ou contextos sociais se enredaram através da superfície da Terra como um todo". Ainda, neste contexto, confirma que:

A globalização pode assim ser definida como a intensificação das relações sociais em escala mundial, que ligam localidades distantes de tal maneira que acontecimentos locais são modelados por eventos ocorrendo a muitas milhas de distância e vice-versa. Este é um processo dialético porque tais acontecimentos locais podem se deslocar numa direção anversa às relações muito distanciadas que os modelam. A transformação local é tanto uma parte da globalização quanto a extensão lateral das conexões sociais através do tempo e do espaço. ${ }^{23}$

Devido às consequências da globalização, as ações dos Estados Nações tornamse impotentes diante do desenvolvimento de relações sociais globalizadas. Com o avanço da globalização, o capital e os fluxos financeiros estão além dos controles dos governos nacionais. Bauman ${ }^{24}$ alega que "o processo de definhamento das Nações Estados acarreta uma catástrofe natural. Suas causas não são plenamente compreendidas; não pode ser previsto com exatidão mesmo que as

21 BAUMAN, Zygmunt. Globalização: as consequências humanas. Tradução de Marcus Penchel. Rio de Janeiro: Jorge Zahar, 1999, p. 8.

22 GIDDENS, Anthony. As consequências da modernidade. Tradução de Raul Fiker. São Paulo: Unesp, 1991, p. 60.

${ }^{23}$ GIDDENS, Anthony. As consequências da modernidade. p. 60.

${ }^{24}$ BAUMAN, Zygmunt. Globalização: as consequências humanas. p. 65. 
CARVALHO, Sonia Aparecida de. Sustentabilidade, Globalização, Tecnologia e Consumo: estratégias de Governança Global. Revista Eletrônica Direito e Política, Programa de Pós-Graduação Stricto Sensu em Ciência Jurídica da UNIVALI, Itajaí, v.10, n.1, edição especial de 2015. Disponível em: www.univali.br/direitoepolitica - ISSN 1980-7791.

causas sejam conhecidas; e, com certeza, não pode ser evitado, mesmo que previsto". Significa que a globalização refere-se a forças anônimas, estendendose para além do alcance da capacidade da ação, tanto do particular quanto do público, como da coletividade e do Estado.

A influência crescente das organizações supranacionais, planetárias, teve por efeito acelerar a exclusão das áreas fracas e criar novos canais para a alocação de recursos, retirados, pelo menos em parte, ao controle dos vários Estados nacionais. [...] A Nação Estado parece que se está desgastando ou talvez definhando. As forças erosivas são transnacionais. Uma vez que as Nações Estados continuam sendo as únicas estruturas para um balanço e as únicas fontes de iniciativa política efetiva, a transnacionalidade das forças erosivas coloca-as fora do reino da ação deliberada, proposital e potencialmente racional. ${ }^{25}$

Nesse sentido, Beck ${ }^{26}$ aponta que a "globalización significa los procesos en virtud de los cuales los Estados nacionales soberanos se entre mezclan e imbrican mediante actores transnacionales y sus respectivas probabilidades de poder y orientaciones". O conceito de globalidade pode reformular as relações, tanto nas dimensões como nas fronteiras da globalização, fundado numa nova política territorial e social. O mesmo autor afirma que "a partir de este concepto de globalidad, el concepto de globalización se puede describir como un proceso que crea vínculos y espacios sociales transnacionales, revaloriza culturas locales y trae a un primer plano terceras culturas". ${ }^{27}$ Consequentemente,

la globalización significa también: ausencia de Estado mundial; más, sociedad mundial sin Estado mundial y sin gobierno mundial. Estamos asistiendo a la difusión de un capitalismo globalmente desorganizado, donde no existe ningun poder hegemónico ni ningún régimen internacional, ya de tipo económico ya político. ${ }^{28}$

\footnotetext{
${ }^{25}$ BAUMAN, Zygmunt. Globalização: as consequências humanas. p. 64.

${ }^{26}$ BECK, Ulrich. ¿Qué es la globalización? Falacias del globalismo, respuestas a la globalización. Barcelona: Paidós, 2004, p. 29.

27 BECK, Ulrich. ¿Qué es la globalización? Falacias del globalismo, respuestas a la globalización. p. 30.

${ }^{28}$ BECK, Ulrich. ¿Qué es la globalización? Falacias del globalismo, respuestas a la globalización. p. 32.
} 
CARVALHO, Sonia Aparecida de. Sustentabilidade, Globalização, Tecnologia e Consumo: estratégias de Governança Global. Revista Eletrônica Direito e Política, Programa de Pós-Graduação Stricto Sensu em Ciência Jurídica da UNIVALI, Itajaí, v.10, n.1, edição especial de 2015. Disponível em: www.univali.br/direitoepolitica - ISSN 1980-7791.

Desse modo, a globalização consiste na ascensão do Estado, da sociedade e do governo mundial, decorrente de um capitalismo globalmente desorganizado, em que inexiste um poder hegemônico.

O avanço do desenvolvimento trouxe o contexto social da produção, trazendo a sociedade de consumo. A difusão do local e do global da modernidade apresenta transformações na vida social moderna, ou seja, modificações na vida diária das pessoas.

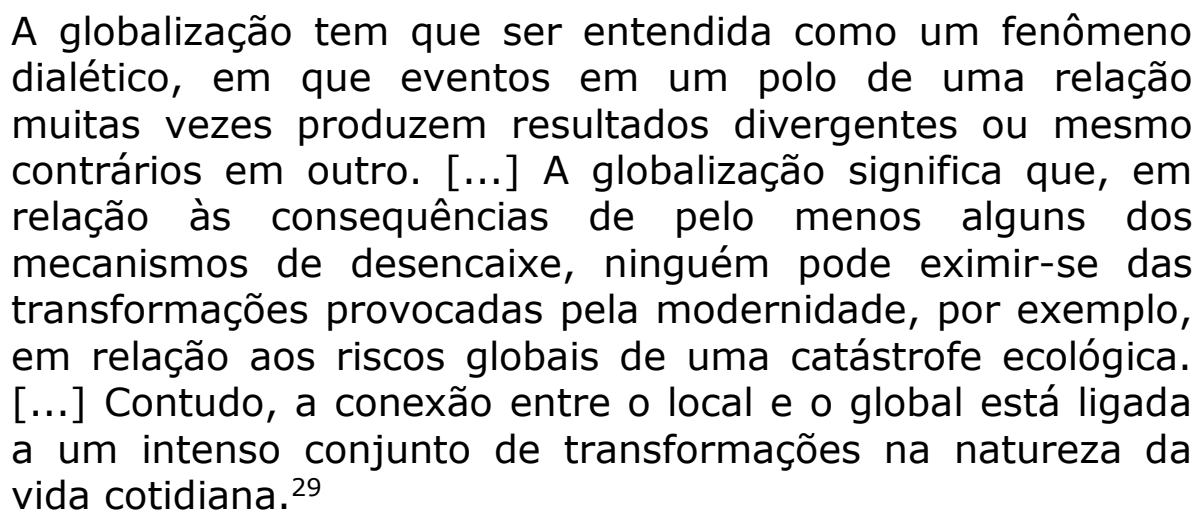

A sociedade moderna molda seus membros em sua condição de consumidores, e não de produtores, pois "a maneira como a sociedade atual molda seus membros é ditado primeiro e acima de tudo pelo dever de desempenhar o papel de consumidor. A norma que nossa sociedade coloca para seus membros é a da capacidade e vontade de desempenhar esse papel". ${ }^{30}$ Significa dizer que a sociedade global de consumo molda seus membros num dever de desempenhar o papel de consumidor.

No entanto, os membros da sociedade de consumidores são considerados mercadorias de consumo. Conforme afirma Bauman ${ }^{31}$, a vida contemporânea e/ou a vida para o consumo ocasiona a transformação das pessoas em mercadoria, pois "numa sociedade de consumidores, em que os vínculos

\footnotetext{
${ }^{29}$ GIDDENS, Anthony. Modernidade e identidade. Tradução de Plínio Dentzien. Rio de Janeiro: Jorge Zahar, 2002, p. 27.

30 BAUMAN, Zygmunt. Globalização: as consequências humanas. Tradução de Marcus Penchel. Rio de Janeiro: Jorge Zahar, 1999, p. 88.

31 BAUMAN, Zygmunt. Vida para consumo: a transformação das pessoas em mercadoria. Tradução de Carlos Alberto Medeiros. Rio de Janeiro: Jorge Zahar, 2008, p. 108.
} 
CARVALHO, Sonia Aparecida de. Sustentabilidade, Globalização, Tecnologia e Consumo: estratégias de Governança Global. Revista Eletrônica Direito e Política, Programa de Pós-Graduação Stricto Sensu em Ciência Jurídica da UNIVALI, Itajaí, v.10, n.1, edição especial de 2015. Disponível em: www.univali.br/direitoepolitica - ISSN 1980-7791.

humanos tendem a ser conduzidos e mediados pelos mercados de bens de consumo", o mercado de consumo tornou a sociedade consumista e levou os seres humanos a uma vida autocentrada, autorreferencial e individualista.

Ainda o mesmo autor alega que "a sociedade de consumidores representa o tipo de sociedade que promove, encoraja ou reforça a escolha de um estilo de vida e uma estratégia existencial consumista, e rejeita todas as opções culturais alternativas". ${ }^{32}$ Em outros termos, a promoção de uma sociedade em que se adaptam as regras da cultura do consumo.

O desenvolvimento da modernidade causa a diferença, a exclusão e a marginalização de indivíduos, assim como as Instituições modernas causam a desigualdade de acesso às formas de realização individual das pessoas na sociedade de consumo.

El estilo de vida refiere también a la toma de decisiones y a los cursos de acción sujetos a condiciones de constricción material; semejantes patrones de estilo de vida, en ocasiones, pueden implicar también el rechazo más o menos deliberado de formas ampliamente difundidas de comportamiento y consumo. ${ }^{33}$

É por meio da interação entre o local e o global que se encontra a transformação da autoidentidade. Além da preocupação com o processo produtivo industrial em larga escala intensifica-se, também, a preocupação com a sociedade de consumo, que se instalou no mundo ocidental em decorrência do capitalismo industrial e em consequência do mercado capitalista.

A percepção dos efeitos colaterais das sociedades afluentes e as críticas ao consumismo materialista são fatores que determinaram essa mudança - surgem novos argumentos contra os hábitos consumistas, deixando evidente que o padrão de consumo das sociedades ocidentais modernas, além de socialmente injustos e moralmente indefensáveis, são ambientalmente insustentáveis. [...] O consumo da

\footnotetext{
32 BAUMAN, Zygmunt. Vida para consumo: a transformação das pessoas em mercadoria. p. 71.

33 GIDDENS, Anthony. Modernidad y autoidentidad. In: GIDDENS, Anthony; BAUMAN, Zygmunt; LUHMANN, Niklas; BECK, Ulrich (Orgs.). Las consecuencias perversas de la modernidad: modernidad, contingencia y riesgo. Traducción de Celso Sánchez Capdequí. Barcelona: Editorial Anthropos, 1996, p. 39.
} 
CARVALHO, Sonia Aparecida de. Sustentabilidade, Globalização, Tecnologia e Consumo: estratégias de Governança Global. Revista Eletrônica Direito e Política, Programa de Pós-Graduação Stricto Sensu em Ciência Jurídica da UNIVALI, Itajaí, v.10, n.1, edição especial de 2015. Disponível em: www.univali.br/direitoepolitica - ISSN 1980-7791.

economia humana tem excedido a capacidade de reprodução natural e assimilação de rejeitos da ecosfera, enquanto faz uso das riquezas produzidas de uma forma socialmente desigual e injusta. Essas duas dimensões, exploração excessiva dos recursos naturais e iniquidade inter $e$ intrageracional na distribuição dos benefícios oriundos dessa exploração, conduziram à reflexão sobre a insustentabilidade ambiental e social dos atuais padrões de consumo. ${ }^{34}$

Apesar dos avanços de grupos sociais e de governos, em escala local e global, o consumo sustentável encontra-se fora das discussões mundiais. São necessários debates sobre a governança global, pois a função da sociedade consiste em consolidar instituições que formulem e promovam práticas que transcendam a ecoeficiência e ampliem a compreensão dos cidadãos sobre os limites do planeta e suas responsabilidades para com as presentes e futuras gerações. Desse modo, a discussão do consumo sustentável deve estar dentro dos assuntos da agenda global. ${ }^{35}$

O consumo sustentável implica necessariamente numa politização do gasto, no sentido de caracterizar as práticas de consumo que transcendem as ações individuais, na medida em que articulem preocupações privadas e questões públicas. A finalidade do consumo sustentável consiste em atender às necessidades do ser humano com o uso mínimo de recursos naturais, dentro dos limites ecológicos do planeta. Consequentemente, a sociedade precisa buscar um equilíbrio entre o que se considera ecologicamente necessário, socialmente desejável e politicamente atingível ou possível. ${ }^{36}$

Por conseguinte, é necessário promover uma política de consumo sustentável fundamentada nas dimensões social, econômica e ambiental, para requerer a

34 GUIMARÃES, Ana Paula Fonseca Valadares; CAMARGO, Serguei Aily Franco de. Consumo e sustentabilidade: um desafio para a administração pública. E-Gov- Portal de E-governo, inclusão digital e sociedade do conhecimento. maio, 2012. Disponível em: http://www.egov.ufsc.br/portal/conteudo/consumo-e-sustentabilidade-um-desafio-paraadministração-pública. Acesso em: 12 abr. 2014, [s. p.].

35 JACOBI, Pedro Roberto. Sustentabilidade ambiental, consumo e cidadania. Revista Ambiente e Sociedade. Campinas, v. 9, n. 1, jan./jun., 2006. Disponível em:

http://www.scielo.br/scielo.php?script=sci_arttext\&pid=S1414-753X2006000100010. Acesso em: 10 abr. 2014, [s. p.].

36 JACOBI, Pedro Roberto. Sustentabilidade ambiental, consumo e cidadania. Revista Ambiente e Sociedade. [s. p.]. 
CARVALHO, Sonia Aparecida de. Sustentabilidade, Globalização, Tecnologia e Consumo: estratégias de Governança Global. Revista Eletrônica Direito e Política, Programa de Pós-Graduação Stricto Sensu em Ciência Jurídica da UNIVALI, Itajaí, v.10, n.1, edição especial de 2015. Disponível em: www.univali.br/direitoepolitica - ISSN 1980-7791.

justiça social com sustentabilidade e politicamente viável, na sociedade moderna transnacional e global.

\section{A DESGOVERNANÇA AMBIENTAL GLOBAL}

A governança significa fortalecer os processos de decisão com a promoção dos instrumentos da democracia participativa, do âmbito local ao global, ou seja, consiste em assumir as responsabilidades globais pela justiça, equidade e sustentabilidade. A governança transnacional, no âmbito global, consiste em um meio ético e participativo de atender aos assuntos públicos de caráter coletivo, em conjunto com as Instituições e Organizações que visam ao desenvolvimento sustentável, que podem, assim, efetivar o princípio democrático e construir um modelo de governança global para conduzir à sustentabilidade.

La consolidación de una ciudadanía global, el reconocimiento del principio democrático junto con el paralelo desarrollo de mecanismos de participación eficaces, y la generación de modelos e instituciones que permitan la gobernanza de lo común en interés de todos. En paralelo a Estados y Organizaciones Internacionales, el impulso político necesario para ordenar el espacio transnacional. ${ }^{37}$

Desse modo, o desenvolvimento de novas estratégias de governança ambiental transnacional, em escala global, implica atitudes solidárias, inclusivas, democráticas e cooperativas, de pessoas ou sociedade civil, Instituições e Estados, objetivando obter uma sociedade mais justa, solidária, inclusiva e sustentável.

Al hablar de gobernanza ambiental se suele pensar en una autoridad ambiental de alcance mundial que sea capaz de imponer reglas de conducta a todos los sujetos, sean ciudadanos, corporaciones o gobiernos, contando con mecanismos coactivos para imponer su autoridad. [...] La sociedad que consideramos sea planetaria, nuestro destino es común y no cabe la sostenibilidad parcial de unas

37 REAL FERRER, Gabriel. Sostenibilidad, transnacionalidad y trasformaciones del Derecho. In: SOUZA, Maria Cláudia da Silva Antunes de; GARCIA, Denise Schmitt Siqueira et al (Orgs.). Direito ambiental, transnacionalidade e sustentabilidade. p. 24. 
CARVALHO, Sonia Aparecida de. Sustentabilidade, Globalização, Tecnologia e Consumo: estratégias de Governança Global. Revista Eletrônica Direito e Política, Programa de Pós-Graduação Stricto Sensu em Ciência Jurídica da UNIVALI, Itajaí, v.10, n.1, edição especial de 2015. Disponível em: www.univali.br/direitoepolitica - ISSN 1980-7791.

comunidades nacionales o regionales al margen de lo que ocurra en el resto del planeta. Construir una comunidad global de ciudadanos activos es indispensable para el progreso de la sostenibilidad. ${ }^{38}$

Assim, com a consolidação de novas estratégias de governança ambiental global, será possível assegurar um futuro com justiça e sustentabilidade. A criação de novas Instituições e Organizações transnacionais mundiais democráticas tem a finalidade de regular e controlar a globalização, a atividade econômica e financeira dos mercados.

A expressão governança global começou a se legitimar entre cientistas sociais e tomadores de decisões a partir do final da década de 1980, basicamente para designar atividades geradoras de instituições que garantem que um mundo formado por Estados Nação se governe sem que disponha de governo central. Atividades para as quais também contribuem muitos atores da sociedade civil, além de governos nacionais e organizações internacionais. ${ }^{39}$

Embora a governança ambiental global e o termo sustentabilidade tenham surgido a partir de 1970, somente ingressam na Agenda internacional na década de 1990. A principal noção de sustentabilidade foi apresentada na Conferência sobre o Meio Ambiente Humano, organizada pelas Nações Unidas sobre o Meio Ambiente, em 1972, passando pelas Conferências sobre Meio Ambiente do Rio92 e do Rio +20.40

Desde a década de 1970, várias instituições ambientais formais e informais, foram criadas com vistas a estabelecer uma nova medida nas relações humanas com o ambiente. No entanto, a proliferação de instituições não garantiu uma melhoria global do estado do ambiente atual. As ações não são coordenadas, o que gerou na Organização das Nações Unidas (ONU) iniciativas com a finalidade de melhorar a coordenação entre as instituições encarregadas da temática ambiental. Com o advento da Conferência das Nações Unidas sobre Desenvolvimento Sustentável, em 2012,

\footnotetext{
38 REAL FERRER, Gabriel. El derecho ambiental y el derecho de la sostenibilidad. Estudios y propuestas para la conservación, A.C.: Abogando por la conservación. [s. p.]. Disponível em: http://eyplc.org/es/articulos. Acesso em: 15 març. 2014, p. 13-14.

39 VEIGA, José Eli da. A desgovernança mundial da sustentabilidade. São Paulo: Editora 34, 2013, p. 13.

40 VEIGA, José Eli da. A desgovernança mundial da sustentabilidade. [s. p.].
} 
CARVALHO, Sonia Aparecida de. Sustentabilidade, Globalização, Tecnologia e Consumo: estratégias de Governança Global. Revista Eletrônica Direito e Política, Programa de Pós-Graduação Stricto Sensu em Ciência Jurídica da UNIVALI, Itajaí, v.10, n.1, edição especial de 2015. Disponível em: www.univali.br/direitoepolitica - ISSN 1980-7791.

conhecida como Rio+20, o debate sobre a regulação das ações humanas em relação ao ambiente está novamente em cena. ${ }^{41}$

A sustentabilidade constitui um novo valor social que surgiu a partir de 1980, e consagrou-se no início de 1990. Entretanto, a legitimação da sustentabilidade como um novo valor é um processo em desenvolvimento, em longo prazo, pois existem vários aspectos que impedem a governança global do desenvolvimento sustentável e da sustentabilidade. ${ }^{42}$ Esses aspectos são "a proliferação de Convenções e Protocolos, com secretariados independentes, ao multiplicar e fragmentar as instâncias decisórias das Nações Unidas"43, o que também contribui para a inviabilização de efetiva governança global do desenvolvimento sustentável e da sustentabilidade. ${ }^{44}$

Segundo afirma Veiga45, "o problema é que a condução do processo de desenvolvimento sustentável e da sustentabilidade não pode resultar da mera coexistência de novas iniciativas de caráter ambiental e velhas ações de desenvolvimento, como ocorre desde a Conferência das Nações Unidas sobre o Meio Ambiente de Estocolmo, em 1972". Há uma desgovernança política mundial da sustentabilidade, referente à atitude ou a maneira global das bases naturais das quais depende o desenvolvimento social, econômico, ambiental e humano.

Ainda, deve durar muito tempo a desgovernança da sustentabilidade. [...] E deve durar, sobretudo, porque tal desgovernança resulta do descompasso histórico entre atividade econômica e ordem política. A acelerada globalização vem sendo acompanhada por inevitável resistência dos processos de soberania nacional, que nem sempre estão sendo acompanhados por avanços da democracia. ${ }^{46}$

\footnotetext{
41 RIBEIRO, Wagner Costa; SANT'ANNA, Fernanda Mello. Governança da ordem ambiental internacional. In: RIBEIRO, Wagner Costa (Org.). Governança da ordem ambiental internacional e inclusão social. São Paulo: Annablume; Procam; IEE, 2012, p. 45.

42 VEIGA, José Eli da. A desgovernança mundial da sustentabilidade. [s. p.].

${ }^{43}$ VEIGA, José Eli da. A desgovernança mundial da sustentabilidade. [s. p.].

${ }^{44}$ VEIGA, José Eli da. A desgovernança mundial da sustentabilidade. [s. p.].

${ }^{45}$ VEIGA, José Eli da. A desgovernança mundial da sustentabilidade. p. 11.

46 VEIGA, José Eli da. A desgovernança mundial da sustentabilidade. p. 131.
} 
CARVALHO, Sonia Aparecida de. Sustentabilidade, Globalização, Tecnologia e Consumo: estratégias de Governança Global. Revista Eletrônica Direito e Política, Programa de Pós-Graduação Stricto Sensu em Ciência Jurídica da UNIVALI, Itajaí, v.10, n.1, edição especial de 2015. Disponível em: www.univali.br/direitoepolitica - ISSN 1980-7791.

Consequentemente, a acelerada globalização da atividade econômica acompanhada dos processos de soberania nacional da ordem política, nem sempre estão seguidos pelos progressos da democracia. Porquanto, as questões ambientais e sociais exigem uma intensa cooperação global dos países e Estados.

Porém, a questão que se impõe é "como entender e interpretar que, após vinte anos da consagração da Conferência das Nações Unidas sobre Meio Ambiente e Desenvolvimento, do Rio-92, intitulada como Agenda 21 e conhecida como agenda do desenvolvimento sustentável"47, não tenha sido desenvolvida uma governança ambiental global. E como compreender que um dos princípios fundamentais da Declaração do Rio-92 - o ambiental - tornou-se ineficaz à sustentabilidade ambiental mundial. ${ }^{48}$

Denota-se que as questões ambientais exigem análises de suas causas, impactos e soluções em escala internacional. Por se tratar da base fundamental à reprodução da vida no planeta, à manutenção do estilo de vida predominante e à constante e crescente demanda por recursos naturais, estimulada por um padrão de consumo exagerado, tornam-se imperativos os modos de governança da ordem ambiental e a regulação das ações humanas em escala global. ${ }^{49}$

Construyamos nuevos modos de gobernanza que aseguren la prevalencia del interés general sobre individualismos insolidarios, sean éstos de individuos, corporaciones 0 Estados. Se trata de politizar la globalización, poniéndola al servicio de las personas y extendiendo mecanismos de gobierno basados en nuevas formas de democracia de arquitectura asimétrica y basadas en la responsabilidad de los ciudadanos. ${ }^{50}$

\footnotetext{
47 VEIGA, José Eli da. A desgovernança mundial da sustentabilidade. p. 112.

48 VEIGA, José Eli da. A desgovernança mundial da sustentabilidade. p. 112.

49 RIBEIRO, Wagner Costa; SANT'ANNA, Fernanda Mello. Governança da ordem ambiental internacional. In: RIBEIRO, Wagner Costa (Org.). Governança da ordem ambiental internacional e inclusão social. São Paulo: Annablume; Procam; IEE, 2012, p. 65.

50 REAL FERRER, Gabriel. El derecho ambiental y el derecho de la sostenibilidad. Estudios y propuestas para la conservación, A.C.: Abogando por la conservación. [s. p.]. Disponível em: http://eyplc.org/es/articulos. Acesso em: 15 març. 2014, p. 14.
} 
CARVALHO, Sonia Aparecida de. Sustentabilidade, Globalização, Tecnologia e Consumo: estratégias de Governança Global. Revista Eletrônica Direito e Política, Programa de Pós-Graduação Stricto Sensu em Ciência Jurídica da UNIVALI, Itajaí, v.10, n.1, edição especial de 2015. Disponível em: www.univali.br/direitoepolitica - ISSN 1980-7791.

A comunidade internacional na Conferência da Rio+20 reiteraram o compromisso com a implantação da Carta da Rio+20 e, com as questões sociais e ambientais que trata o Programa das Nações Unidas para o Meio Ambiente (PNUMA). Os países reconheceram que um meio ambiente saudável é fundamental para os Objetivos do Desenvolvimento Sustentável (ODS) e, solicitaram a promoção de padrões de consumo e produção sustentáveis.

A governança ambiental no âmbito da Organização das
Nações Unidas (ONU) poderá avançar somente se houver
real fortalecimento do Programa das Nações Unidas para o
Meio Ambiente (PNUMA) e efetiva substituição da Comissão
de Desenvolvimento Sustentável pelo Fórum de Alto Nível.
Todavia, enquanto não for possível alterar o sistema
decisório, o mais provável é que os avanços mais
significativos venham a exigir prévias e decisivas
mobilizações do G-20.51 a Conforme comenta Veiga52 "a governança global da sustentabilidade espera da Organização das Nações Unidas (ONU), que os Objetivos de Desenvolvimento Sustentável (ODS), venham a substituir em 2015, os atuais Objetivos de Desenvolvimento do Milênio (ODM)". Diante disso, na Conferência da Rio+20, os países solicitaram a integração da dimensão ambiental no processo do desenvolvimento sustentável e o reconhecimento de que um meio ambiente saudável é essencial para os Objetivos do Desenvolvimento Sustentável (ODS).

Percebe-se, nesse contexto, a sustentabilidade como uma nova estratégia de governança transnacional global, com ações solidárias, democráticas e cooperativas da sociedade civil, das Instituições e dos Estados, almejando-se obter uma sociedade justa, solidária, inclusiva e sustentável. A consolidação do direito à sustentabilidade social, econômica e ambiental, decidirá o futuro do planeta e a sustentabilidade definirá o vindouro das gerações, que é formado pelo meio ambiente, pela sociedade e pela tecnologia.

El derecho de la sostenibilidad deberé articularse como un derecho transnacional cuyo fundamento no trae causa de las soberanías nacionales, sino de la nueva sociedad global.

\footnotetext{
51 VEIGA, José Eli da. A desgovernança mundial da sustentabilidade. p. 78.

52 VEIGA, José Eli da. A desgovernança mundial da sustentabilidade. p. 133.
} 
CARVALHO, Sonia Aparecida de. Sustentabilidade, Globalização, Tecnologia e Consumo: estratégias de Governança Global. Revista Eletrônica Direito e Política, Programa de Pós-Graduação Stricto Sensu em Ciência Jurídica da UNIVALI, Itajaí, v.10, n.1, edição especial de 2015. Disponível em: www.univali.br/direitoepolitica - ISSN 1980-7791.

Trae parte de la estructura clásica de los órdenes jurídico, social, económico y ambiental, que son propios de los Estados soberanos, pero desborda claramente ese ámbito. Su vocación es aportar soluciones que sirvan a todos, sin importar donde se encuentren o donde nacieron. Pretende aportar la esperanza de una sociedad futura global y mejor. ${ }^{53}$

Portanto, a implantação de um sistema de solidariedade, de cooperação e de participação e atuação conjunta dos cidadãos, dos Estados, das Instituições e das Organizações, destinam-se a obter uma governança global da sustentabilidade, assim como uma sociedade justa, solidária e sustentável.

\section{CONSIDERAÇÕES FINAIS}

O artigo demonstra que há uma relação intrínseca entre a sustentabilidade, a globalização, a tecnologia e o consumo. Consequentemente, proteger o meio ambiente e o ser humano são os objetivos da técnica, baseados na sustentabilidade.

Diante dessa perspectiva, o artigo evidencia que o desenvolvimento da sustentabilidade e da tecnologia visa buscar o equilíbrio entre os fatores econômicos, sociais, ambientais e tecnológicos, assim como o avanço da globalização e do consumo aponta interações econômicas, sociais, políticas e culturais, por meio da governança transnacional e mundial.

Por conseguinte, comprova que o desenvolvimento de novas estratégias de governança ambiental transnacional, em escala global, implica atitudes solidárias, inclusivas, democráticas e cooperativas de pessoas ou da sociedade civil, de Instituições e de Estados, objetivando uma sociedade mais justa, solidária, inclusiva e sustentável.

Por fim, a sustentabilidade significa a ruptura da humanidade, da crise de civilização e da crise ecológica e/ou ambiental, colapsos que alcançam o período

53 REAL FERRER, Gabriel. El derecho ambiental y el derecho de la sostenibilidad. Estudios y propuestas para la conservación, A.C.: Abogando por la conservación. p. 9. 
CARVALHO, Sonia Aparecida de. Sustentabilidade, Globalização, Tecnologia e Consumo: estratégias de Governança Global. Revista Eletrônica Direito e Política, Programa de Pós-Graduação Stricto Sensu em Ciência Jurídica da UNIVALI, Itajaí, v.10, n.1, edição especial de 2015. Disponível em: www.univali.br/direitoepolitica - ISSN 1980-7791.

culminante na transição da modernidade para a pós-modernidade, marcado pela diversidade ambiental, social, econômica, cultural e política.

\section{REFERÊNCIAS DAS FONTES CITADAS}

BAUMAN, Zygmunt. Globalização: as consequências humanas. Tradução de Marcus Penchel. Rio de Janeiro: Jorge Zahar, 1999.

Vida para consumo: a transformação das pessoas em mercadoria. Tradução de Carlos Alberto Medeiros. Rio de Janeiro: Jorge Zahar, 2008.

BECK, Ulrich. ¿Qué es la globalización? Falacias del globalismo, respuestas a la globalización. Barcelona: Paidós, 2004.

CRUZ, Paulo Márcio; BODNAR, Zenildo (Orgs.). Globalização, transnacionalidade e sustentabilidade. Itajaí: UNIVALI, 2012. Disponível em: http://www.univali.br/ppcj/ebook. Acesso em: 5 mai. 2013.

JACOBI, Pedro Roberto. Sustentabilidade ambiental, consumo e cidadania. Revista Ambiente e Sociedade. Campinas, v. 9, n. 1, jan./jun., 2006. Disponível em: http://www.scielo.br/scielo.php?script=sci_arttext\&pid=S1414753X2006000100010. Acesso em: 10 abr. 2014.

Meio ambiente e sustentabilidade. In: CEPAM. O Município no século XXI: cenários e perspectivas. São Paulo: CEPAM, 1999, p. 175-183. Disponível em: http://pt.scribd.com/doc/7506458/Meio-Ambiente-e-Sustentabilidade. Acesso em: 15 abr. 2014.

JONAS, Hans. O princípio responsabilidade: ensaio de uma ética para a civilização tecnológica. Tradução de Marijane Lisboa; Luiz Barros Montez. Rio de Janeiro: Contraponto; PUC-RJ, 2006.

GIDDENS, Anthony. As consequências da modernidade. Tradução de Raul Fiker. São Paulo: Unesp, 1991. 
CARVALHO, Sonia Aparecida de. Sustentabilidade, Globalização, Tecnologia e Consumo: estratégias de Governança Global. Revista Eletrônica Direito e Política, Programa de Pós-Graduação Stricto Sensu em Ciência Jurídica da UNIVALI, Itajaí, v.10, n.1, edição especial de 2015. Disponível em: www.univali.br/direitoepolitica - ISSN 1980-7791.

Modernidade e identidade. Tradução de Plínio Dentzien. Rio de Janeiro: Jorge Zahar, 2002.

. Modernidad y autoidentidad. In: GIDDENS, Anthony; BAUMAN, Zygmunt; LUHMANN, Niklas; BECK, Ulrich (Orgs.). Las consecuencias perversas de la modernidad: modernidad, contingencia y riesgo. Traducción de Celso Sánchez Capdequí. Barcelona: Editorial Anthropos, 1996, p. 33-71.

GUIMARÃES, Ana Paula Fonseca Valadares; CAMARGO, Serguei Aily Franco de. Consumo e sustentabilidade: um desafio para a administração pública. E-GovPortal de E-governo, inclusão digital e sociedade do conhecimento. maio, 2012. Disponível em: http://www.egov.ufsc.br/portal/conteudo/consumo-esustentabilidade-um-desafio-para-administração-pública. Acesso em: 12 abr. 2014.

LEFF, Enrique. Saber ambiental: sustentabilidade, racionalidade, complexidade, poder. Tradução de Lúcia Mathilde Endlich Orth. 8. ed. Petrópolis: Vozes, 2011.

LUIZ, Leliana Aparecida Casagrande. Educação ambiental e desenvolvimento sustentável: gestão ambiental. São Paulo: Pearson Prentice Hall, 2009.

REAL FERRER, Gabriel. Sostenibilidad, transnacionalidad y trasformaciones del Derecho. In: SOUZA, Maria Cláudia da Silva Antunes de; GARCIA, Denise Schmitt Siqueira et al (Orgs.). Direito ambiental, transnacionalidade e sustentabilidade. Itajaí: UNIVALI, 2013, p. 7-30. Disponível em: http://www.univali.br/ppcj/ebook. Acesso em: 10 set. 2013. 
CARVALHO, Sonia Aparecida de. Sustentabilidade, Globalização, Tecnologia e Consumo: estratégias de Governança Global. Revista Eletrônica Direito e Política, Programa de Pós-Graduação Stricto Sensu em Ciência Jurídica da UNIVALI, Itajaí, v.10, n.1, edição especial de 2015. Disponível em: www.univali.br/direitoepolitica - ISSN 1980-7791.

La construcción del derecho ambiental. Novos Estudos Jurídicos NEJ. Itajaí-SC, v. 18, n. 3, p. 347- 368, set./dez., 2013. Disponível em: http://siaiweb06.univali.br/seer/index.php/nej/article/view/5128/2688. Acesso em: 15 març. 2014.

Calidad de vida, medio ambiente, sostenibilidad y ciudadanía ¿construimos juntos el futuro? Novos Estudos Jurídicos - NEJ. Itajaí-SC, v. 17, n. 3, p. 310-326, set./dez., 2012. Disponível em: http://siaiweb06.univali.br/seer/index.php/nej/article/view/4202/2413. Acesso em: 15 març. 2014.

- El derecho ambiental y el derecho de la sostenibilidad. Estudios y propuestas para la conservación, A.C.: Abogando por la conservación. [s.p.]. Disponível em: http://eyplc.org/es/articulos. Acesso em: 15 març. 2014.

RIECHMANN, Jorge; REYES, Luis González; HERRERO, Yayo; MADORRÁN, Carmen (Orgs.). Qué hacemos hoy cuando nos encontramos frente a la amenaza de una crisis mayor que la económica: la ecológica. Madrid: Ediciones Akal, S. A., 2012.

RIBEIRO, Wagner Costa; SANT'ANNA, Fernanda Mello. Governança da ordem ambiental internacional. In: RIBEIRO, Wagner Costa (Org.). Governança da ordem ambiental internacional e inclusão social. São Paulo: Annablume; Procam; IEE, 2012, p. 45-68.

SANTOS, Boaventura de Sousa. Os processos da globalização. In: SANTOS, Boaventura de Sousa (Org.). A globalização e as ciências sociais. 2. ed. São Paulo: Cortez, 2002, p. 25-102.

VEIGA, José Eli da. A desgovernança mundial da sustentabilidade. São Paulo: Editora 34, 2013.

Submetido em: Agosto/2014

Aprovado em: Outubro/2014 